This item was submitted to Loughborough's Research Repository by the author.

Items in Figshare are protected by copyright, with all rights reserved, unless otherwise indicated.

\title{
Whey protein does not enhance the adaptations to elbow flexor resistance training
}

PLEASE CITE THE PUBLISHED VERSION

http://dx.doi.org/10.1249/MSS.0b013e318256c48d

\section{PUBLISHER}

(c) The American College of Sports Medicine

\section{VERSION}

AM (Accepted Manuscript)

\section{PUBLISHER STATEMENT}

This work is made available according to the conditions of the Creative Commons Attribution-NonCommercialNoDerivatives 4.0 International (CC BY-NC-ND 4.0) licence. Full details of this licence are available at: https://creativecommons.org/licenses/by-nc-nd/4.0/

\section{LICENCE}

CC BY-NC-ND 4.0

\section{REPOSITORY RECORD}

Erskine, Robert M., Gareth Fletcher, Beth Hanson, and Jonathan P. Folland. 2019. "Whey Protein Does Not Enhance the Adaptations to Elbow Flexor Resistance Training”. figshare. https://hdl.handle.net/2134/16028. 
Whey Protein does not Enhance the Adaptations to Elbow Flexor Resistance

\section{Training}

Robert M. Erskine ${ }^{1}$, Gareth Fletcher ${ }^{2}$, Beth Hanson ${ }^{2}$ and Jonathan P. Folland ${ }^{2}$

${ }^{1}$ Institute for Performance Research, Department of Exercise and Sport Science, Manchester

Metropolitan University, Crewe, United Kingdom; ${ }^{2}$ School of Sport, Exercise and Health Sciences,

Loughborough University, Loughborough, United Kingdom.

Address correspondence to: J.P. Folland, School of Sport, Exercise and Health

Sciences, Loughborough University, Loughborough, LE11 3TU, United Kingdom;

Tel: +44 (0)1509 226334; Fax: +44 (0)1509 226301; Email: J.P.Folland@lboro.ac.uk

Running title: Protein supplementation and strength training

Funding disclosure: This study was funded by GlaxoSmithKline Nutritional Healthcare UK.

Conflict of interest: There is no conflict of interest declared by any of the authors. 


\section{ABSTRACT}

Purpose: It is unclear whether protein supplementation augments the gains in muscle strength and size observed following resistance training (RT), as limitations to previous studies include small cohorts, imprecise measures of muscle size and strength, and no control of prior exercise or habitual protein intake (HPI). We aimed to determine whether whey protein supplementation affected RT-induced changes in elbow flexor muscle strength and size. Methods: We pair-matched 33 previously untrained, healthy young men for their HPI and strength response to 3-wk RT without nutritional supplementation (followed by 6-wk no training), and then randomly assigned them to protein (PRO; $n=17$ ) or placebo (PLA; $n=16$ ) groups. Participants subsequently performed elbow flexor RT $3 \mathrm{~d} /$ wk for 12-wk and consumed PRO or PLA immediately before and after each training session. We assessed elbow flexor muscle strength [unilateral 1-RM and isometric maximum voluntary force (MVF)] and size [total volume and maximum anatomical cross-sectional area (ACSA $\mathrm{Amax}_{\text {ma }}$ ) determined with MRI] before and after the 12-wk RT. Results: PRO and PLA demonstrated similar increases in muscle volume (PRO, $17.0 \pm 7.1 \%$ vs. PLA, $14.9 \pm$ 4.6\%; $P=0.32), \mathrm{ACSA}_{\max }(\mathrm{PRO}, 16.2 \pm 7.1 \%$ vs. PLA, $15.6 \pm 4.4 \% ; P=0.80), 1-$ RM (PRO, $41.8 \pm 21.2 \%$ vs. PLA, $41.4 \pm 19.9 \% ; P=0.97)$ and MVF (PRO, $12.0 \pm$ 9.9\% vs. PLA, $14.5 \pm 8.3 \%$; $P=0.43$ ). Conclusion: In the context of this study, protein supplementation did not augment elbow flexor muscle strength and size changes that occurred after 12-wk RT.

Key words: Protein supplementation - strength training - muscle hypertrophy muscle architecture - training response 


\section{INTRODUCTION}

Paragraph Number (PN) 1: Both resistance exercise (4) and protein ingestion (31) are known to stimulate muscle protein synthesis (MPS), which is necessary for the accretion of skeletal muscle mass. Moreover, combining protein or amino acid ingestion with an acute bout of resistance exercise has been shown to further augment MPS (32). Based on these acute studies, it is surprising that the evidence for protein supplementation (PRO) enhancing the gains in muscle size and strength following longer term RT programs in young men remains equivocal $(17,24)$.

PN 2: It has been suggested that the muscle strength $(9,40)$ and size $(1,17)$ responses to RT in young men may be amplified by PRO, although these effects are often marginal (20). In contrast, other studies in young men have shown no effect of PRO on gains in muscle size $(8,24)$ or strength $(1,24)$. Greater increases in muscle fiber area $(1,17)$ and myofibrillar protein content $(40)$ have been observed when RT was combined with PRO rather than carbohydrate. However, none of these studies included detailed measurements of whole muscle size.

PN 3: The apparent discrepancy between the acute studies of a single training bout and the longer-term RT studies may be compounded by a range of methodological issues with the latter. Firstly, the individual response to RT is known to vary widely between individuals $(13,19)$, yet numerous studies have used small participant groups $(16,20,40)$ that may not have been powered to detect an influence of PRO. The impact of inter-individual variability might also be reduced by greater experimental control of prior physical activity and habitual protein intake. Secondly, some studies have used crude measures of muscle hypertrophy, such as dual-energy X-ray 
absorptiometry to assess whole body fat-free mass (17) or muscle thickness determined with ultrasonography $(7,35)$. Thirdly, in the context of nutritional supplementation, no study has attempted to minimize or quantify the neural changes that occur with RT, which together with muscle hypertrophy, are considered the major contributors to strength improvements (15). Thus, large and variable neural improvements could have confounded the potential influence of PRO on traininginduced changes in muscle size and strength in previous studies. Finally, the resistance exercise model that has been most commonly researched has involved lower limb training $(1,8,34)$ despite the upper limb musculature showing greater adaptive responses to resistance training $(10,37)$. Therefore, an elbow flexor exercise model may offer a better chance of discriminating an influence of PRO on muscle hypertrophy and strength changes following RT.

PN 4: Taking all the above factors into account, we aimed to compare the traininginduced changes in elbow flexor muscle size, architecture and strength between two groups of previously untrained young men supplemented with either protein or placebo. We hypothesized that $20 \mathrm{~g}$ (26) whey protein (31) ingested immediately before (33) and after (14) each training session would confer greater changes in muscle size and strength after 12 weeks of RT, compared to RT alone.

\section{METHODS}

\section{Participants}

PN 5: Thirty-three healthy young men (mean \pm SD: age, $23 \pm 3$ yrs; height, $1.76 \pm$ $0.06 \mathrm{~m}$; body mass, $75.2 \pm 10.7 \mathrm{~kg}$ ) provided written informed consent prior to completing this 25-week study, which complied with the Declaration of Helsinki and 
was approved by the Ethical Advisory Committee of Loughborough University. Volunteers were excluded from taking part in the study if they: were vegans; had unusually high $\left(>2 \mathrm{~g} \cdot \mathrm{kg}^{-1} \cdot \mathrm{day}^{-1}\right)$ or low $\left(<0.8 \mathrm{~g} \cdot \mathrm{kg}^{-1} \cdot \mathrm{day}^{-1}\right)$ protein intake (see below); reported use of potentially anabolic supplements in the previous 6 months or were taking any medication considered to influence muscle size or function; had a history of upper body exercise in the previous 12 months; were $<18$ or $>30$ yrs old.

\section{Study overview}

PN 6: The study was a single-centre, double-blind design. Participants completed 3wk elbow flexor RT without nutritional supplementation, 6-wk of no training, and then 12-wk elbow flexor RT with nutritional supplementation (Fig. 1A). The 3-wk RT period was conducted to standardize training status prior to the 12-wk RT, and to overcome neural adaptations that occur within the first few weeks of RT (27). The 6wk of no training provided a clear break between the training periods to improve participant retention, and has been shown to result in only a modest detraining effect (23). During the 6-wk no RT participants were pair-matched for their isometric strength response to the 3-wk RT and their normal protein intake (Table 1), and randomly assigned to PRO $(n=17)$ or PLA $(n=16)$ supplementation groups. The groups had similar age, elbow flexor muscle strength and size, anthropometric, physical activity and nutritional characteristics (Table 1). Participants then completed 12-wk RT, during which they received PRO or PLA supplementation. Measurements of the dominant arm were performed before and 3-4 days after the 12-wk RT in the following order: muscle architecture (assessed with ultrasonography); dynamic and isometric strength (agonist and antagonist muscle activation was determined with sEMG); muscle size was assessed with magnetic resonance imaging (MRI) at least 
24-h after strength testing to ensure that measurements were not influenced by exercise-induced fluid shifts. All testing took place between 09:00 and 18:00 and, for each participant, tests were performed at the same time of day before and after training. Participants were instructed not to participate in strenuous physical activity, consume alcohol or excessive amounts of caffeine in the 24-hr prior to measurement sessions, and to maintain their habitual diet and lifestyle throughout the study.

Table 1 near here.

\section{Resistance training (RT)}

PN 7: During both RT periods participants performed 3 training sessions per week (Monday, Wednesday and Friday). Each session commenced with unilateral bicep curls using dumbbells and a modified preacher bench (Body Solid, Forest Park, IL) and sets were performed alternately with each arm. Subsequently, bilateral bicep curls were performed on a resistance training machine (Pro Club Line Bicep Curl; Body Solid, Forest Park, IL). The loading for both exercises was 8-10 RM and the load was increased when participants could lift 10 reps during the final set of an exercise. The 3-wk RT involved 2 sets of each exercise, i.e. 2 sets for each unilateral arm exercise; 2 sets bilateral, with 2 min rest between each set. This was the same for wk 1-2 of the 12-wk RT, but increased to 3 sets (unilateral) and 2 sets (bilateral) during wk 3-4 and 3 sets of both exercises for wk 5-12. Apart from the supplementation provided, participants were instructed to consume only water in the $2 \mathrm{hr}$ before and $1.5 \mathrm{hr}$ after each training session, and to facilitate this, training sessions took place either midmorning (10:00 to 11:00) or mid afternoon (14:30 to 16.30$)$. Furthermore, every participant completed all 36 training sessions. 


\section{Supplementation}

PN 8: Participants were given their supplementation in a double-blind manner in the form of an opaque drinks bottle containing $250 \mathrm{ml}$ fluid, which was fully consumed immediately before, and another immediately after, each RT session. The PRO supplement comprised water mixed with 30 g powder that contained 20 g whey protein ( $\sim 50 \%$ essential amino acids), 6.7 g lactose, together with flavoring and sweeteners. Thus, the total protein supplementation on training days was $40 \mathrm{~g} \cdot \mathrm{d}^{-1}$, and when averaged across training and non-training days, the PRO supplement increased protein intake by $17.1 \mathrm{~g} \cdot \mathrm{d}^{-1}$, carbohydrate intake by $5.7 \mathrm{~g} \cdot \mathrm{d}^{-1}$ and energy intake by $91.2 \mathrm{kcal} \cdot \mathrm{d}^{-1}$. Each PLA supplement contained $6.8 \mathrm{~g}$ of lactose and, when averaged over training and non-training days, increased carbohydrate intake by $5.8 \mathrm{~g} \cdot \mathrm{d}^{-1}$ and energy intake by $23.2 \mathrm{kcal} \cdot \mathrm{d}^{-1}$.

\section{Neuromuscular measurements and protocol}

\section{Muscle architecture}

PN 9: Fascicle pennation angle $\left(\theta_{\mathrm{p}}\right.$, the angle between the fascicular paths and their insertion into the deep aponeurosis) of the biceps brachii short head (BBS) and brachialis (BRACH) muscles was examined using B-mode ultrasonography (SSA37OA Power Vision 6000, Toshiba, Otawara-Shi, Japan) with an 8 MHz linear-array transducer. Participants lay supine with the dominant elbow extended and the shoulder abducted by $90^{\circ}$. Strips of ultrasound-absorbent tape (2 mm wide; 3M, Neuss, Germany) were placed perpendicular to the long axis of the BBS at $50 \mathrm{~mm}$ intervals from the cubital crease to the shoulder, which formed markers on the sonographs and enabled $\theta_{\mathrm{p}}$ to be analyzed at the same location pre and post RT. A 
midline between the medial and lateral boundaries of the BBS was marked along the length of the muscle. The probe (coated with gel) was applied to the cubital crease with minimal pressure and carefully glided along this line to the proximal end of BBS (in line with the direction of the muscle fascicles). Sonographs were analyzed offline using a public domain software package (NIH ImageJ, Bethesda, MD). Fascicle $\theta_{\mathrm{p}}$ was determined in $3 \mathrm{BBS}$ fascicles within $50 \mathrm{~mm}$ of its distal end and in $3 \mathrm{BRACH}$ fascicles within $50 \mathrm{~mm}$ of its proximal end. The mean of the three measurements determined $\theta_{\mathrm{p}}$ for each muscle and the test-retest coefficient of variation (CV) for this assessment was $2.9 \%$.

\section{Unilateral single repetition maximum (1-RM)}

PN 10: Unilateral bicep curl 1-RM lifting strength was assessed with a series of incremental dumbbell lifts using the modified preacher bench that was used in training. The bench was customized with a horizontal rack at full elbow extension, which provided a consistent starting position for the 1-RM lift. The height of the padded arm support was adjusted to arm length, ensuring the elbow was fully extended when the hand gripped the dumbbell on the rack. The warm-up comprised 10 reps at $40 \%$ of the previous $1-\mathrm{RM}$ and, after 1 min rest, 3 reps were performed at $80 \%$ of the previous 1-RM. Thereafter, a series of single lifts (concluding at full flexion, at which point the investigator removed the dumbbell from the participant) were performed interspersed with 1 min rest intervals, firstly at the previous 1-RM, and then at increments of $+0.5 \mathrm{~kg}$ if the preceding lift was successful. The 1 - $\mathrm{RM}$ was generally determined within 3-5 attempts, although more attempts were completed if necessary. The test-retest CV for this assessment was 3.5\%. 
Isometric maximum voluntary force (MVF)

PN 11: Elbow flexor isometric strength was measured using a custom-built strengthtesting chair (Fig. 1B) and the elbow joint angle fixed at $120^{\circ}\left(180^{\circ}=\right.$ full elbow extension). The participant sat upright (hip joint angle of $90^{\circ}$ ) and was strapped at the hip and chest to the seat and back of the chair to prevent movement of the body. The shoulder joint was flexed to $90^{\circ}$ with the upper arm placed on a horizontal board, and externally rotated with the elbow position maintained by blocks anterior and lateral to the joint. The forearm was supinated, and the wrist strapped to an S-Beam tensioncompression load cell (Applied Measurements Ltd, Aldermaston, UK), which was positioned perpendicular to the direction of forearm movement during isometric elbow flexion/extension. The force signal was interfaced with an analogue to digital converter (CED micro 1401, Cambridge, UK), sampled at $2000 \mathrm{~Hz}$ with a PC using Spike 2 software (CED, Cambridge, UK) and low-pass filtered (500 Hz edge frequency) with a second order Butterworth digital filter. Following a warm up of four submaximal voluntary contractions, participants completed four elbow flexion isometric maximum voluntary contractions (MVCs) separated by $\geq 30 \mathrm{~s}$, in which they were instructed to flex the elbow as hard as possible for $3 \mathrm{~s}$. Biofeedback and verbal encouragement were provided during and in between each MVC. Participants then completed four isometric elbow extension MVCs with an identical protocol to determine the maximum surface EMG (sEMG $\max$ ) amplitude of the TB (see details below). MVF for elbow flexion and extension was the greatest instantaneous voluntary force achieved during that action and the test-retest CV for this assessment was $3.4 \%$.

Fig. 1 near here. 


\section{Surface electromyography (sEMG)}

PN 12: Surface EMG (Delsys Bagnoli-4, Boston, MA) was recorded from three agonist muscles (BBS, BBL and BR), and one antagonist muscle [lateral head of $\mathrm{m}$. triceps brachii (TB)]. Following preparation of the skin (shaving, lightly abrading and cleansing with 70\% ethanol), double-differential surface electrodes (1 cm interelectrode distance, Model DE-3.1; Delsys, Boston, MA) were attached over the belly of each muscle, parallel to the presumed orientation of the muscle fibers using adhesive interfaces, and a reference electrode placed on the clavicle. BBS and BBL electrodes were placed mid-belly at $25 \%$ of the distance from the medial epicondyle of the humerus to the coracoid process, i.e. distal to the motor point region of each head (22). The BR electrode was placed over the proximal third of the muscle belly, identified during a submaximal isometric "hammer curl”. Similarly, the TB electrode was placed over the distal third of the lateral head of the TB muscle, identified during a submaximal isometric elbow extension. Electrode locations were recorded for subsequent tests by measuring the distance from the centre of the electrode to the cubital crease (BBS, BBL and BR) or olecranon process (TB) with the elbow fully extended. Surface EMG signals were amplified (x100, differential amplifier 20-450 $\mathrm{Hz}$ ) and sampled at $2000 \mathrm{~Hz}$ with the same analogue to digital converter and PC as the force signal, prior to being band-pass filtered $(6-500 \mathrm{~Hz})$ using a 4th order zerolag Butterworth filter. The root mean square (RMS) of the sEMG signal of a $500 \mathrm{~ms}$ epoch around MVF ( $\pm 250 \mathrm{~ms}$ ) was used to assess activation of agonist and antagonist muscles. To minimize the variability in absolute sEMG (6), sEMG recorded at elbow flexion MVF was normalized to the evoked supramaximal $M$-wave (compound muscle action potential), or $M_{\max }$, of the BBS and BBL (see below) and elbow 


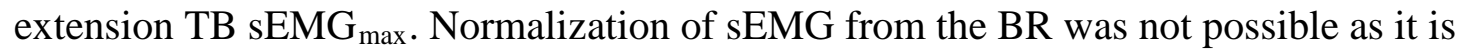
not innervated purely by the musculocutaneous nerve, and thus a reliable $M_{\max }$ cannot be evoked.

\section{Neural stimulation and evoked $M_{\max }$}

PN 13: A self-adhesive anode ( 5 x $5 \mathrm{~cm}$; Verity Medical, Andover, UK) was attached to the skin over the TB muscle. The cathode $(1 \mathrm{~cm}$ diameter, Electro Medical Supplies, Wantage, UK) was held to the skin over the musculocutaneous nerve, in between the BBS and BBL, at 50\% of the distance between the medial epicondyle of the humerus and the coracoid process [the motor point of the BB muscle (22)]. The precise location of the cathode was determined as the position that, upon electrical stimulation (DS7AH, Digitimer Ltd., Welwyn Garden City, UK) with single square wave pulses (0.2 ms duration), evoked the greatest $M$-wave response from BBS and BBL for a particular submaximal electrical current (typically 3-5 stimuli at 30-50 $\mathrm{mA}$ ). $M$-waves were then evoked at 10-20 mA incremental current intensities until a plateau was achieved (typically between 80-140 mA). Thereafter, the electrical current was increased by $20 \%$ and three supramaximal $M$-waves were evoked. $M_{\max }$ was defined as the mean peak-to-peak sEMG response to these 3 stimuli.

\section{Muscle size}

PN 14: A Magnetom Symphony 1.5-T MRI scanner (Siemens AG, Erlangen, Germany) was used to perform three overlapping scans (each comprising 25 contiguous axial 'slices' perpendicular to the humerus/radius) from the acromion process to below the distal end of the radius of the dominant arm, which was secured in supination to minimize movement while the participant lay supine. The following 
parameters were used for each T1-weighted scan: time of repetition $420 \mathrm{~ms}$; time to echo 1.2 sec; matrix 284 x 448 pixels; field of view 181 x 200 mm; slice thickness 10 $\mathrm{mm}$; interslice gap $0 \mathrm{~mm}$. The scans were subsequently imported to a dicom image viewer (Osirix Foundation, Geneva, Switzerland) and using the lipid capsules that were placed on the skin mid-way along the humerus and radius, and anatomical markers (e.g. bone, blood vessel size, etc.), the relevant slice from the first scan was matched with the identical slice in the second scan, and so on. The ACSA of each muscle of interest (BB, BRACH and BR) was then manually outlined (excluding visible fat and connective tissue) and plotted against bone length (proximal end of the humerus to the distal end of the radius). A spline curve was fitted to the ACSA data points of each muscle and volume was calculated as the area under the curve (12); the sum of the three volumes provided total elbow flexor muscle volume. The largest ACSA ( $\mathrm{ACSA}_{\max }$ ) was recorded for $\mathrm{BB}, \mathrm{BRACH}$ and $\mathrm{BR}$, and the sum of the three $\mathrm{ACSA}_{\max }$ provided $\sum \mathrm{ACSA} \mathrm{A}_{\max }$. The test-retest $\mathrm{CV}$ for the assessment of total volume and $\sum \mathrm{ACSA}_{\max }$ was $0.8 \%$ and $0.9 \%$, respectively.

\section{Nutrient intake, anthropometry and physical activity}

PN 15: Participants used 'Arc' electronic weighing scales (Salter, Tonbridge, UK) to weigh and record their nutrient intake for 3 days (Thursday-Saturday) during both the 3-wk and 12-wk RT periods (Fig. 1A). Records were scrutinized by a sports nutritionist and analyzed with Compeat v5.8 (Pro) software (Nutrition Systems, Grantham, UK). Participants who had an unusually high $\left(>2 \mathrm{~g} \cdot \mathrm{kg}^{-1} \cdot \mathrm{d}^{-1}\right)$ or low $(<0.8$ $\mathrm{g} \cdot \mathrm{kg}^{-1} \cdot \mathrm{d}^{-1}$ ) protein intake during the 3-wk RT were excluded from the supplemented 12-wk RT. Body mass and height were measured in conjunction with skin-fold thickness, which was assessed in duplicate at four sites (biceps, triceps, subscapular 
and iliac crest) using Harpenden skin-fold calipers (Baty International, Burgess Hill, UK), as changes in subcutaneous fat are likely to influence the sEMG signal and, therefore, the assessment of muscle activation. Further, \% body fat was calculated from the sum of these four skin-folds $(11,30)$ and used to calculate fat-free mass. The test-retest CV for the assessment of \% body fat was $0.8 \%$. Habitual physical activity level (PAL) was assessed from a standard questionnaire (2) that was completed at the start and end of the whole study protocol (Fig. 1A).

\section{Statistical analysis}

PN 16: Analyses of raw data recordings were completed by the same investigator, who remained blinded to supplement group. Group data are expressed as mean \pm standard deviation (SD). Between group comparisons for pre- and post-RT absolute values were compared with 2-way repeated measures ANOVA (group: PLA vs. PRO; time: pre vs. post). Comparisons between groups pre-training or for $\%$ change over the 12-wk supplemented RT period were performed with independent $t$-tests. Bivariate relationships were assessed with Pearson's product moment correlations and statistical significance was defined as $P<0.05$.

\section{RESULTS}

\section{Muscle size and architecture}

PN 17: After 12 wks supplemented RT, total elbow flexor muscle volume increased from $413.4 \pm 73.1$ to $474.1 \pm 80.1 \mathrm{~cm}^{3}(+17.0 \pm 7.1 \%)$ for PRO and from $388.3 \pm 61.9$ to $454.8 \pm 81.5 \mathrm{~cm}^{3}(+14.9 \pm 4.6 \%)$ for PLA, with no significance difference between the two groups (ANOVA, time $P<0.001$, group $\mathrm{x}$ time $P=0.52$; Table 2). The training-induced change in volume of the individual elbow flexors also showed no 
effect of supplementation group (ANOVA, group x time: $\mathrm{BB}, P=0.86$; $\mathrm{BRACH}, P=$ 0.68; BR, $P=0.77$; Fig. 2A; Table 2).

PN 18: $\sum \mathrm{ACSA}_{\max }$ also displayed a clear effect of the training from $26.9 \pm 4.3$ to 31.3 $\pm 5.1 \mathrm{~cm}^{2}(+16.2 \pm 7.1 \%)$ for PRO and from $28.5 \pm 3.9$ to $32.9 \pm 4.5 \mathrm{~cm}^{2}(+15.6 \pm$ 4.4\%) for PLA, but no difference between the groups (ANOVA, time $P<0.001$, group x time $P=0.87$; Table 2). Similarly, the changes in $\mathrm{ACSA}_{\max }$ for each of the individual elbow flexor muscles were not influenced by supplementation (ANOVA, group x time $0.53<P<0.95$; Table 2).

PN 19: Training increased muscle fascicle $\theta_{\mathrm{p}}$ of the BBS and BRACH in both the PRO (BBS, $18.5 \pm 9.5 \%$; BRACH, $15.7 \pm 9.9 \%$ ) and PLA (BBS, $15.8 \pm 6.9 \%$; BRACH, $14.6 \pm 8.2 \%$ ) supplementation groups, but these changes did not differ between the groups (ANOVA, group x time $0.65<P<0.89$; Table 2).

Table 2 near here.

\section{Muscle strength}

PN 20: Isometric MVF of the elbow flexors increased after 12-wks RT, but to a similar extent for both groups [PLA, $271.2 \pm 43.0$ to $309.7 \pm 48.8 \mathrm{~N}(+14.5 \pm 8.3 \%)$; PRO, $253.8 \pm 41.1$ to $283.8 \pm 50.1$ N (+12.0 $\pm 9.9 \%)$; ANOVA, time $P<0.001$, group x time $P=0.32$; Fig. 2B]. Following the 12-wk RT period, 1-RM lifting strength increased, although there was no difference between groups [PLA, $13.3 \pm 3.2$ to 18.3 $\pm 3.7 \mathrm{~kg}(+41.4 \pm 19.9 \%) ; \mathrm{PRO}, 12.3 \pm 2.7$ to $17.2 \pm 3.7 \mathrm{~kg}(41.8 \pm 21.2 \%)$; ANOVA, time $P<0.001$, group $\mathrm{x}$ time $P=0.90$; Fig. 2B). 
Fig. 2 near here.

\section{Neurological changes during isometric elbow flexion}

PN 21: Two of the agonist muscles showed a drop in absolute sEMG at isometric maximum voluntary force (MVF) after training (ANOVA, time: BBL, $P=0.045$; BBS, $P=0.049$; BR $P=0.17$; Table 3 ), but there were similar changes in $M_{\max }$ and hence normalized sEMG was unchanged after training (ANOVA, time, BBL $P=$ 0.173; BBS, $P=0.56$; Table 3). There was no interaction between supplementation group and RT for agonist sEMG (ANOVA, group x time: absolute values, $0.11<P<$ 0.80; normalized values, $0.60<P<0.95$; Table 3). The percentage change in sEMG at isometric MVF also showed no difference between groups for the individual agonist muscles (Table 3). When data were collapsed across the agonist muscles there were no differences between the \% changes recorded for the supplementation groups (absolute values: PLA, $-9.5 \pm 17.5 \%$ vs. PRO, $-2.5 \pm 27.6 \%$, $t$-test $P=0.41$; normalized values: PLA, $6.1 \pm 34.1 \%$ vs. PRO, $0.0 \pm 34.9 \%$, $t$-test $P=0.63$ ). Antagonist sEMG at elbow flexion MVF was unchanged in both groups (ANOVA, group x time: absolute values, $P=0.09$; normalized values, $P=0.65$ ).

Table 3 near here.

\section{Nutrient intake, anthropometry and physical activity}

$\boldsymbol{P N}$ 22: There were no differences between groups in their normal dietary intake of energy or macronutrients during the 3-wk (Table 1) or supplemented 12-wk RT (Table 4), and no changes over time, either in absolute terms or normalized to body 
mass (ANOVA, time $P \geq 0.459$; group x time $P \geq 0.312$; Table 4 ). On training days during the 12-wk RT, protein intake was significantly higher in PRO compared to PLA, both in absolute terms (PLA, $101.2 \pm 27.2 \mathrm{~g} \cdot \mathrm{d}^{-1}$ vs. PRO, $139.6 \pm 22.8 \mathrm{~g} \cdot \mathrm{d}^{-1} ; t$ test, $P<0.0005$ ) and when normalized to body mass (PLA, $1.35 \pm 0.47 \mathrm{~g} \cdot \mathrm{kg}^{-1} \cdot \mathrm{d}^{-1}$ vs. PRO, $1.88 \pm 0.37 \mathrm{~g} \cdot \mathrm{kg}^{-1} \cdot \mathrm{d}^{-1}$; $t$-test, $P=0.002$; Table 4). However, when supplement intake was averaged across training and non-training days, total protein intake was similar for both groups (absolute values; $t$-test, $P=0.09$; normalized to body mass; $t$ test, $P=0.12$; Table 4 ), and carbohydrate, fat and total energy intake remained similar (t-test, $P \geq 0.47$; Table 4).

PN 23: Subcutaneous fat increased after the 12-wk RT period (ANOVA, time $P=$ 0.03) but there was no group interaction (ANOVA, group x time $P=0.09$ ). There was a significant effect of the supplemented RT period on body mass (ANOVA, time $P=$ 0.005 ) and \% body fat (ANOVA, time $P=0.022$ ) over the 12 -wk supplemented RT period. However, the changes in body mass (ANOVA, group x time $P=0.17$; PLA, $75.6 \pm 11.4$ to $77.1 \pm 11.5 \mathrm{~kg} ; \mathrm{PRO}, 74.9 \pm 10.3$ to $75.5 \pm 10.0 \mathrm{~kg})$ and $\%$ body fat (ANOVA, group x time, $P=0.09$; PLA, $21.5 \pm 6.1$ to $23.1 \pm 6.3 \%$; PRO, $22.5 \pm 5.1$ to $22.7 \pm 4.9 \%$ ) were similar for the two groups. There were no changes in FFM during the supplemented RT (ANOVA, time $P=0.58$, group x time $P=0.55$; PLA, $60.2 \pm 10.2$ to $60.2 \pm 9.6 \mathrm{~kg} ; \mathrm{PRO}, 57.9 \pm 7.5$ to $58.2 \pm 7.1 \mathrm{~kg})$.

PN 24: Prior to performing the 3-wk RT, the whole cohort had a PAL of $2.6 \pm 0.4$ indicating that they were 'recreationally active', and it remained stable over the course of the study (post 12-wk RT, $2.6 \pm 0.4$ ). There was no difference in PAL between PLA and PRO (ANOVA, time $P=0.36$, group x time $P=0.48$ ), and the 
mean PAL (pre and post) was unrelated to any of the training responses following the 12-wk RT $\left(R^{2} \leq 0.06 ; P \geq 0.17\right)$.

Table 4 near here.

\section{DISCUSSION}

PN 25: The aim of this study was to determine the effect of protein supplementation (PRO) on changes in elbow flexor muscle size, architecture and strength following 12 weeks of RT. By using sensitive, state of the art techniques, we found that PRO did not influence any of these training-induced adaptations.

PN 26: There are a number of factors in our study that we thought would accentuate an effect of PRO on the training-induced changes in muscle size and strength: 1) it featured larger cohorts than have been used in most previous studies of this kind; 2) an initial pre-intervention RT period was included to overcome neural changes, standardize pre-intervention training status and familiarize participants with all training and measurement procedures; 3) participants included only young, healthy male participants that might be more responsive to RT (37) and PRO (36) than older individuals; 4) we employed an upper-limb RT program to maximize the muscle hypertrophic response. The measurements incorporated 1.5T MRI for documenting changes in muscle size, ultrasonographic assessments of muscle architecture, as well as careful functional measurements. In addition, possible confounding factors were considered prospectively by pair matching participants according to their normal nutrient intake and isometric strength response to the initial 3-wk of RT prior to their 
random allocation to supplementation groups, and retrospectively by assessing normal dietary behavior and neural drive.

PN 27: The $\sim 16 \%$ changes in elbow flexor muscle volume and maximum ACSA observed in this study were similar to the $14-23 \%$ changes reported in previous upper limb RT studies $(10,19,37)$. In spite of these substantial changes, there was no difference in muscle hypertrophy between PRO and PLA groups. Accepting the methodological differences between studies, this finding is broadly similar to previous investigations in young men $(8,20)$, post-menopausal women $(18)$ and older people (34), which used MRI $(8,18,20)$ or computer tomography (34) to quantify changes in lower-limb muscle ACSA following RT supplemented with PRO or PLA. The lowerlimb nature of these previous strength training studies resulted in markedly smaller changes in muscle size (5-10\%) compared to those reported in our study, and thus may have restricted their capacity to determine any hypertrophic benefit of PRO. However, despite using a more responsive muscle group, our results suggest that PRO does not amplify the hypertrophic adaptation to RT.

PN 28: In contrast, some previous studies have used other measures of muscularity, such as dual-energy X-ray absorptiometry to assess lean body mass (17) and ultrasonography to measure muscle thickness (7), and have found a positive effect of PRO following a period of RT. However, these methods are widely considered to have lower precision and reliability than MRI (3). Furthermore, other RT studies have reported no difference between PRO and PLA regarding changes in either lean body mass (34) or muscle thickness (35). By measuring muscle fiber CSA (fCSA), the effect of PRO on RT-induced muscle hypertrophy has been determined at the cellular 
level but with contradictory findings $(1,17,18,34)$. The lack of concurrence may reflect the large variability in the histological measurement of fCSA from biopsy samples (25) that may not mirror training-induced changes in whole muscle size measured with MRI (28).

PN 29: We observed significant increases in biceps brachii and brachialis muscle fascicle pennation angle $\left(\theta_{\mathrm{p}}\right)$ in both PRO and PLA groups but no difference between groups. These findings are in accord with the relative changes in whole muscle volume and $\mathrm{ACSA}_{\max }$ observed in both training groups but are in contrast to those of a previous RT study that reported an increase in gastrocnemius medialis $\theta_{\mathrm{p}}$ in participants supplemented with essential amino acids and no change in PLA (35). This is surprising, especially as RT is known to increase muscle $\theta_{\mathrm{p}}$ even when no nutritional supplementation is provided (13).

PN 30: Together with muscle hypertrophy, neural changes are considered to be the major contributors to strength improvements following RT (15) and the current study was the first to quantify the neural adaptations to RT in the context of PRO. Voluntary muscle activation and antagonist muscle co-activation, assessed with normalized sEMG, did not change following 12 weeks elbow flexion RT in either group. This finding suggests that elbow flexor muscle activation was very high prior to the 12-wk RT period, and that neural adaptations did not confound any potential effect of PRO on the strength gains found in this study.

PN 31: Following the 12-wk supplemented RT, elbow flexor 1-RM increased by $\sim 41 \%$ and isometric strength by $\sim 13 \%$, changes that are in accord with previous RT 
studies on the elbow flexor muscle group (10). However, given that there were no differences in neural adaptations or muscle morphology between PRO and PLA groups, it was not surprising that RT-induced strength gains did not differ between the two groups. This finding is similar to that reported in previous RT studies of the lower limb $(1,17,34)$ but different to those reporting a significant effect of PRO on RTinduced increases in 1-RM $(8,9)$. Although the reasons for these discrepancies are not clear, changes in 1-RM are probably influenced by neural adaptations and the involvement of stabilizer muscles (29), which were not accounted for in these studies and may have confounded their results.

PN 32: Normal dietary behavior, as assessed from two 3-day records of weighed nutrient intake, was similar for the PRO and PLA groups both before and during the 12-wk supplemented RT period, and there was no change over time. Therefore, it seems unlikely that this could have confounded our findings. However, we acknowledge that a longer recording period and/or additional assessments of weighed nutrient intake might have provided a more comprehensive account of habitual diet and further reinforced our results. Based on the available evidence, we considered that whey protein as opposed to soy or casein (31), supplemented immediately before and after each session $(14,33)$, as well as a dosage of $\geq 20 \mathrm{~g}(26)$, would promote MPS, and maximize the hypertrophic response. The conventional PRO supplementation approach of this study, i.e. targeted at the time of training, did influence protein intake on training days, but did not affect total protein intake averaged over training and non-training days. It is possible, therefore, that influencing total protein intake could be an important factor in any benefits of PRO, although several previous studies that also found no influence of training targeted PRO on total protein intake $(17,20)$ did 
find positive effects of PRO on indicators of muscle hypertrophy (17) or strength responses (20).

PN 33: While the timing of PRO with respect to a resistance exercise bout has previously been shown to influence the augmentation of MPS following a single bout of resistance exercise (33), some recent work indicates that the sensitivity of MPS to PRO persists for up to $24 \mathrm{~h}$ after a bout of resistance exercise (5). Therefore, it is feasible that prolonged sensitivity to MPS following each training session in our study may have enabled the protein content within the regular meals of the PLA group to stimulate similar net protein synthesis to the PRO group. Furthermore, although PRO has been found to elevate the anabolic hormone response to multiple-limb resistance exercise (21), higher levels of circulating anabolic hormones following multiple-limb versus solely upper-limb RT do not appear to affect acute MPS (39) or chronic muscle hypertrophy (38). However, while the focus of the current study was on the functional and hypertrophic changes with chronic RT, the acute MPS and hormonal responses may have helped inform these effects, and future work should consider acute MPS and hormonal changes alongside chronic adaptations. Considering the relatively small muscle mass trained, and the equivalent training responses of the two groups, the habitual protein intake of both groups may have been sufficient to maintain optimal net protein synthesis, thus facilitating similar accretion of muscle mass. In this case the available free amino acids within the muscle and blood of the PLA group may have been adequate to satisfy the protein requirements for increased synthesis following each RT bout. It is feasible, therefore, that RT incorporating a much greater muscle mass, such as whole body RT, could have a higher protein requirement and might benefit from the provision of supplementary protein. However, the few studies 
that have used MRI to assess muscle hypertrophy following RT of multiple muscle groups have demonstrated that PRO has either a marginal (20) or no effect (18).

PN 34: In conclusion, protein supplementation did not augment the adaptations of muscle strength and size that occurred after 12 weeks of elbow flexor RT in previously untrained young men. We suggest that future studies should use similar sensitive measures of muscle size and strength to investigate whether the adaptations to RT in different circumstances may be more responsive to protein supplementation, such as whole body RT.

\section{ACKNOWLEDGEMENTS}

We thank GlaxoSmithKline Nutritional Healthcare UK for funding the project and the participants for their effort and commitment to the study. The results of this study do not constitute endorsement by ACSM.

\section{CONFLICT OF INTERESTS}

There is no conflict of interest declared by any of the authors. 


\section{REFERENCES}

1. Andersen LL, Tufekovic G, Zebis MK, Crameri RM, Verlaan G, Kjaer M, Suetta $\mathrm{C}$, Magnusson $\mathrm{P}$, and Aagaard P. The effect of resistance training combined with timed ingestion of protein on muscle fiber size and muscle strength. Metabolism. 2005;54(2):151-6.

2. Baecke JA, Burema J, and Frijters JE. A short questionnaire for the measurement of habitual physical activity in epidemiological studies. Am J Clin Nutr. 1982;36(5):936-42.

3. Bamman MM, Newcomer BR, Larson-Meyer DE, Weinsier RL, and Hunter GR. Evaluation of the strength-size relationship in vivo using various muscle size indices. Med Sci Sports Exerc. 2000;32(7):1307-13.

4. Biolo G, Maggi SP, Williams BD, Tipton KD, and Wolfe RR. Increased rates of muscle protein turnover and amino acid transport after resistance exercise in humans. Am J Physiol. 1995;268(3 Pt 1):E514-20.

5. Burd NA, West DW, Moore DR, Atherton PJ, Staples AW, Prior T, Tang JE, Rennie MJ, Baker SK, and Phillips SM. Enhanced amino acid sensitivity of myofibrillar protein synthesis persists for up to $24 \mathrm{~h}$ after resistance exercise in young men. J Nutr. 2011;141(4):568-73.

6. Burden A. How should we normalize electromyograms obtained from healthy participants? What we have learned from over 25 years of research. $J$ Electromyogr Kinesiol. 2010;20(6):1023-35.

7. Candow DG, Little JP, Chilibeck PD, Abeysekara S, Zello GA, Kazachkov M, Cornish SM, and Yu PH. Low-dose creatine combined with protein during resistance training in older men. Med Sci Sports Exerc. 2008;40(9):1645-52.

8. Coburn JW, Housh DJ, Housh TJ, Malek MH, Beck TW, Cramer JT, Johnson GO, and Donlin PE. Effects of leucine and whey protein supplementation during eight weeks of unilateral resistance training. J Strength Cond Res. 2006;20(2):284-91.

9. Cribb PJ, Williams AD, Stathis CG, Carey MF, and Hayes A. Effects of whey isolate, creatine, and resistance training on muscle hypertrophy. Med Sci Sports Exerc. 2007;39(2):298-307.

10. Cureton KJ, Collins MA, Hill DW, and McElhannon FM, Jr. Muscle hypertrophy in men and women. Med Sci Sports Exerc. 1988;20(4):338-44.

11. Durnin JV, and Womersley J. Body fat assessed from total body density and its estimation from skinfold thickness: measurements on 481 men and women aged from 16 to 72 years. Br J Nutr. 1974;32(1):77-97.

12. Erskine RM, Jones DA, Maganaris CN, and Degens H. In vivo specific tension of the human quadriceps femoris muscle. Eur J Appl Physiol. 2009;106(6):827-38. 
13. Erskine RM, Jones DA, Williams AG, Stewart CE, and Degens H. Interindividual variability in the adaptation of human muscle specific tension to progressive resistance training. Eur J Appl Physiol. 2010;110(6):1117-25.

14. Esmarck B, Andersen JL, Olsen S, Richter EA, Mizuno M, and Kjaer M. Timing of postexercise protein intake is important for muscle hypertrophy with resistance training in elderly humans. J Physiol. 2001;535(Pt 1):301-11.

15. Folland JP, and Williams AG. The adaptations to strength training : morphological and neurological contributions to increased strength. Sports Med. 2007;37(2):145-68.

16. Godard MP, Williamson DL, and Trappe SW. Oral amino-acid provision does not affect muscle strength or size gains in older men. Med Sci Sports Exerc. 2002;34(7):1126-31.

17. Hartman JW, Tang JE, Wilkinson SB, Tarnopolsky MA, Lawrence RL, Fullerton AV, and Phillips SM. Consumption of fat-free fluid milk after resistance exercise promotes greater lean mass accretion than does consumption of soy or carbohydrate in young, novice, male weightlifters. Am J Clin Nutr. 2007;86(2):373-81.

18. Holm L, Olesen JL, Matsumoto K, Doi T, Mizuno M, Alsted TJ, Mackey AL, Schwarz P, and Kjaer M. Protein-containing nutrient supplementation following strength training enhances the effect on muscle mass, strength, and bone formation in postmenopausal women. J Appl Physiol. 2008;105(1):274-81.

19. Hubal MJ, Gordish-Dressman H, Thompson PD, Price TB, Hoffman EP, Angelopoulos TJ, Gordon PM, Moyna NM, Pescatello LS, Visich PS, Zoeller RF, Seip RL, and Clarkson PM. Variability in muscle size and strength gain after unilateral resistance training. Med Sci Sports Exerc. 2005;37(6):964-72.

20. Hulmi JJ, Kovanen V, Selanne H, Kraemer WJ, Hakkinen K, and Mero AA. Acute and long-term effects of resistance exercise with or without protein ingestion on muscle hypertrophy and gene expression. Amino Acids. 2009;37(2):297-308.

21. Kraemer WJ, Volek JS, Bush JA, Putukian M, and Sebastianelli WJ. Hormonal responses to consecutive days of heavy-resistance exercise with or without nutritional supplementation. J Appl Physiol. 1998;85(4):1544-55.

22. Lee JH, Kim HW, Im S, An X, Lee MS, Lee UY, and Han SH. Localization of motor entry points and terminal intramuscular nerve endings of the musculocutaneous nerve to biceps and brachialis muscles. Surg Radiol Anat. 2010;32(3):213-20.

23. Lemmer JT, Hurlbut DE, Martel GF, Tracy BL, Ivey FM, Metter EJ, Fozard JL, Fleg JL, and Hurley BF. Age and gender responses to strength training and detraining. Med Sci Sports Exerc. 2000;32(8):1505-12. 
24. Lemon PW, Tarnopolsky MA, MacDougall JD, and Atkinson SA. Protein requirements and muscle mass/strength changes during intensive training in novice bodybuilders. J Appl Physiol. 1992;73(2):767-75.

25. Lexell J, and Taylor CC. A morphometrical comparison of right and left whole human vastus lateralis muscle: how to reduce sampling errors in biopsy techniques. Clin Physiol. 1991;11(3):271-6.

26. Moore DR, Robinson MJ, Fry JL, Tang JE, Glover EI, Wilkinson SB, Prior T, Tarnopolsky MA, and Phillips SM. Ingested protein dose response of muscle and albumin protein synthesis after resistance exercise in young men. Am J Clin Nutr. 2009;89(1):161-8.

27. Moritani T, and deVries HA. Neural factors versus hypertrophy in the time course of muscle strength gain. Am J Phys Med. 1979;58(3):115-30.

28. Narici MV, Hoppeler H, Kayser B, Landoni L, Claassen H, Gavardi C, Conti M, and Cerretelli P. Human quadriceps cross-sectional area, torque and neural activation during 6 months strength training. Acta Physiol Scand. 1996;157(2):175-86.

29. Rutherford OM, and Jones DA. The role of learning and coordination in strength training. Eur J Appl Physiol Occup Physiol. 1986;55(1):100-5.

30. Siri WE. Body composition from fluid space and density. In: J Brozek and A Hanschel editors. Techniques for measuring body composition. Washington DC: National Academy of Science; 1961, pp. 223-44.

31. Tang JE, Moore DR, Kujbida GW, Tarnopolsky MA, and Phillips SM. Ingestion of whey hydrolysate, casein, or soy protein isolate: effects on mixed muscle protein synthesis at rest and following resistance exercise in young men. $J$ Appl Physiol. 2009;107(3):987-92.

32. Tipton KD, Ferrando AA, Phillips SM, Doyle D, Jr., and Wolfe RR. Postexercise net protein synthesis in human muscle from orally administered amino acids. Am J Physiol. 1999;276(4 Pt 1):E628-34.

33. Tipton KD, Rasmussen BB, Miller SL, Wolf SE, Owens-Stovall SK, Petrini BE, and Wolfe RR. Timing of amino acid-carbohydrate ingestion alters anabolic response of muscle to resistance exercise. Am J Physiol Endocrinol Metab. 2001;281(2):E197-206.

34. Verdijk LB, Jonkers RA, Gleeson BG, Beelen M, Meijer K, Savelberg HH, Wodzig WK, Dendale P, and van Loon LJ. Protein supplementation before and after exercise does not further augment skeletal muscle hypertrophy after resistance training in elderly men. Am J Clin Nutr. 2009;89(2):608-16.

35. Vieillevoye S, Poortmans JR, Duchateau J, and Carpentier A. Effects of a combined essential amino acids/carbohydrate supplementation on muscle mass, architecture and maximal strength following heavy-load training. Eur J Appl Physiol. 2010;110(3):479-88. 
36. Volpi E, Mittendorfer B, Rasmussen BB, and Wolfe RR. The response of muscle protein anabolism to combined hyperaminoacidemia and glucose-induced hyperinsulinemia is impaired in the elderly. J Clin Endocrinol Metab. 2000;85(12):4481-90.

37. Welle S, Totterman S, and Thornton C. Effect of age on muscle hypertrophy induced by resistance training. J Gerontol A Biol Sci Med Sci. 1996;51(6):M2705.

38. West DW, Burd NA, Tang JE, Moore DR, Staples AW, Holwerda AM, Baker SK, and Phillips SM. Elevations in ostensibly anabolic hormones with resistance exercise enhance neither training-induced muscle hypertrophy nor strength of the elbow flexors. J Appl Physiol. 2010;108(1):60-7.

39. West DW, Kujbida GW, Moore DR, Atherton P, Burd NA, Padzik JP, De Lisio M, Tang JE, Parise G, Rennie MJ, Baker SK, and Phillips SM. Resistance exercise-induced increases in putative anabolic hormones do not enhance muscle protein synthesis or intracellular signalling in young men. $J$ Physiol. 2009;587(Pt 21):5239-47.

40. Willoughby DS, Stout JR, and Wilborn CD. Effects of resistance training and protein plus amino acid supplementation on muscle anabolism, mass, and strength. Amino Acids. 2007;32(4):467-77. 


\section{FIGURE LEGENDS}

FIGURE 1. Overview of the study intervention periods and measurements (A): 1-RM, single repetition maximum; $M V F$, isometric maximum voluntary force (incl. sEMG); MRI, magnetic resonance imaging to assess muscle size; $U S$, ultrasound measurements of muscle architecture; anthropometry, skinfold measurements, body mass and height; Nutrient intake, food and drink intake weighed and recorded over 3days; $P A L$, physical activity level assessed via questionnaire; and the isometric strength testing apparatus $(B)$ used to measure elbow flexion and extension MVF.

FIGURE 2. Relative training-induced changes in $(A)$ elbow flexor muscle volume and (B) isometric maximum voluntary force (MVF) and single repetition maximum (1$\mathrm{RM}$ ) after 12 weeks of resistance training with placebo (PLA) or protein (PRO) supplementation; $B B$, biceps brachii; $B R A C H$, brachialis; $B R$, brachioradialis; TOTAL, all 3 elbow flexor muscles; relative changes did not differ between PLA and PRO groups $(P>0.05)$; values are mean \pm SD. 
TABLE 1. Characteristics of the PRO and PLA groups before the 12-wk supplemented RT period.

\begin{tabular}{lccc}
\hline Variable & $\begin{array}{c}\text { PLA } \\
(n=16)\end{array}$ & $\begin{array}{c}\text { PRO } \\
(n=17)\end{array}$ & $\begin{array}{c}t \text {-test } \\
P=\end{array}$ \\
\hline Age (yr) & $23.7 \pm 2.9$ & $23.1 \pm 3.0$ & 0.59 \\
Body mass (kg) & $75.6 \pm 11.4$ & $74.9 \pm 10.3$ & 0.87 \\
Height (cm) & $177.0 \pm 6.5$ & $175.9 \pm 6.5$ & 0.65 \\
\% body fat & $22.1 \pm 6.2$ & $22.5 \pm 5.1$ & 0.85 \\
Habitual physical activity rating & $2.62 \pm 0.44$ & $2.50 \pm 0.34$ & 0.37 \\
Energy intake $\left(\mathrm{kcal} \cdot \mathrm{d}^{-1}\right)$ & $2515 \pm 706$ & $2482 \pm 581$ & 0.89 \\
Protein intake $\left(\mathrm{g} \cdot \mathrm{d}^{-1}\right)$ & $101 \pm 21$ & $94 \pm 24$ & 0.39 \\
Protein intake (g. $\left.\cdot \mathrm{kg}^{-1} \cdot \mathrm{d}^{-1}\right)$ & $1.36 \pm 0.35$ & $1.26 \pm 0.31$ & 0.41 \\
Isometric MVF $(\mathrm{N})$ & $271.2 \pm 43.0$ & $253.8 \pm 41.1$ & 0.24 \\
1RM (kg) & $13.3 \pm 3.2$ & $12.3 \pm 2.7$ & 0.37 \\
Isometric strength response to the initial 3-wk & $+5.6 \pm 7.5$ & $+4.9 \pm 12.9$ & 0.85 \\
RT period $(\%)$ & & & \\
Elbow flexor muscle volume $\left(\mathrm{cm}^{3}\right)$ & $413.4 \pm 73.1$ & $388.3 \pm 61.9$ & 0.29 \\
Elbow flexor muscle $\sum \mathrm{ACSA}_{\max }\left(\mathrm{cm}^{2}\right)$ & $28.5 \pm 3.9$ & $26.9 \pm 4.3$ & 0.29 \\
\hline
\end{tabular}

Data are means $\pm \mathrm{SD}$, and independent $t$-test $P$ values are displayed. 
TABLE 2. Elbow flexor muscle volume, maximum anatomical cross-sectional area (ACSA $\mathrm{max}_{\text {) }}$ and muscle fascicle pennation $\left(\theta_{\mathrm{p}}\right)$ angle before (Pre) and after (Post) the 12-wk RT period, with placebo (PLA) or protein (PRO) supplementation before and after every training session. Data are mean \pm SD and ANOVA group x time (g x t) $P$-values are displayed.

\begin{tabular}{|c|c|c|c|c|c|}
\hline & \multicolumn{2}{|c|}{$\operatorname{PLA}(n=16)$} & \multicolumn{2}{|c|}{$\mathrm{PRO}(n=17)$} & \multirow{2}{*}{$\begin{array}{l}\mathrm{g} \times \mathrm{t} \\
P=\end{array}$} \\
\hline & Pre & Post & Pre & Post & \\
\hline \multicolumn{6}{|l|}{ Muscle Volume $\left(\mathrm{cm}^{3}\right)$} \\
\hline Biceps Brachii & $184.6 \pm 35.7$ & $214.7 \pm 39.4$ & $172.1 \pm 29.1$ & $203.0 \pm 37.9$ & 0.86 \\
\hline Brachialis & $156.7 \pm 28.5$ & $176.4 \pm 31.0$ & $150.1 \pm 28.4$ & $174.3 \pm 36.7$ & 0.68 \\
\hline Brachioradialis & $71.6 \pm 16.5$ & $82.3 \pm 17.5$ & $65.6 \pm 12.5$ & $76.9 \pm 15.5$ & 0.77 \\
\hline Total & $413.4 \pm 73.1$ & $474.1 \pm 80.1$ & $388.3 \pm 61.9$ & $454.8 \pm 81.5$ & 0.52 \\
\hline \multicolumn{6}{|l|}{$\mathrm{ACSA}_{\max }\left(\mathrm{cm}^{2}\right)$} \\
\hline Biceps Brachii & $12.0 \pm 2.3$ & $14.0 \pm 2.7$ & $11.1 \pm 1.9$ & $13.0 \pm 2.3$ & 0.54 \\
\hline Brachialis & $12.3 \pm 1.5$ & $14.0 \pm 1.6$ & $11.8 \pm 2.0$ & $13.6 \pm 2.5$ & 0.80 \\
\hline Brachioradialis & $4.2 \pm 0.8$ & $4.9 \pm 0.8$ & $4.0 \pm 0.8$ & $4.7 \pm 0.9$ & 0.94 \\
\hline$\sum \mathrm{ACSA}_{\max }$ & $28.5 \pm 3.9$ & $32.9 \pm 4.5$ & $26.9 \pm 4.3$ & $31.3 \pm 5.1$ & 0.87 \\
\hline \multicolumn{6}{|l|}{$\theta_{\mathrm{p}}\left(^{\circ}\right)$} \\
\hline Biceps Brachii & $15.1 \pm 3.0$ & $17.5 \pm 3.8$ & $13.7 \pm 2.4$ & $16.2 \pm 2.9$ & 0.89 \\
\hline Brachialis & $10.5 \pm 1.6$ & 12.01 .8 & $11.0 \pm 1.7$ & $12.6 \pm 1.5$ & 0.65 \\
\hline
\end{tabular}


TABLE 3. Surface EMG activity at isometric elbow flexion maximum voluntary force (MVF) before (Pre) and after (Post) the 12-wk RT period, with placebo (PLA) or protein (PRO) supplementation. Data are expressed in absolute values and normalized to: $M_{\max }$ (agonist muscles: BBL and BBS) or maximum sEMG during elbow extension (antagonist muscle: triceps brachii, TB). Data are mean \pm SD and $P$-values are shown for ANOVA group x time $(\mathrm{g} \mathrm{x} \mathrm{t)}$ interaction effect and independent $t$-tests for the percentage change $(\% \Delta)$.

\begin{tabular}{|c|c|c|c|c|c|c|c|c|c|}
\hline \multirow{2}{*}{$\begin{array}{l}\text { Measure: } \\
\text { Muscle }\end{array}$} & & \multicolumn{3}{|c|}{$\operatorname{PLA}(n=16)$} & \multicolumn{3}{|c|}{$\operatorname{PRO}(n=17)$} & \multirow{2}{*}{$\begin{array}{l}\text { ANOVA } \\
\text { gxt } P=\end{array}$} & \multirow{2}{*}{$\begin{array}{l}t \text {-test } \\
\% \Delta P=\end{array}$} \\
\hline & & Pre & Post & $\% \Delta$ & Pre & Post & $\% \Delta$ & & \\
\hline \multicolumn{10}{|c|}{ Absolute Values (mV): } \\
\hline \multirow[t]{6}{*}{ Agonists: } & $\mathrm{BR}$ & 0.75 & 0.73 & -0.8 & 0.67 & 0.62 & 5.6 & 0.80 & 0.58 \\
\hline & & \pm 0.38 & \pm 0.38 & \pm 26.4 & \pm 0.46 & \pm 0.33 & \pm 37.7 & & \\
\hline & BBL & 0.84 & 0.68 & -11.3 & 0.59 & 0.48 & -10.6 & 0.11 & 0.95 \\
\hline & & \pm 0.54 & \pm 0.48 & \pm 35.2 & \pm 0.38 & \pm 0.31 & \pm 33.6 & & \\
\hline & BBS & 1.24 & 0.94 & -15.6 & 1.08 & 0.88 & -6.2 & 0.70 & 0.54 \\
\hline & & \pm 0.81 & \pm 0.65 & \pm 36.9 & \pm 0.71 & \pm 0.47 & \pm 46.6 & & \\
\hline \multirow[t]{2}{*}{ Antagonist: } & TB & 0.02 & 0.02 & 12.6 & 0.02 & 0.01 & -13.3 & 0.09 & 0.14 \\
\hline & & \pm 0.03 & \pm 0.01 & \pm 53.1 & \pm 0.03 & \pm 0.01 & \pm 44.0 & & \\
\hline \multicolumn{10}{|c|}{ Normalized Values (\%): } \\
\hline \multirow[t]{4}{*}{ Agonists: } & BBL & 8.8 & 7.5 & -0.9 & 9.6 & 8.5 & -1.9 & 0.91 & 0.95 \\
\hline & & \pm 5.4 & \pm 3.1 & \pm 46.7 & \pm 7.2 & \pm 4.5 & \pm 38.6 & & \\
\hline & BBS & 10.0 & 10.3 & 13.1 & 12.8 & 10.7 & 2.0 & 0.46 & 0.60 \\
\hline & & \pm 9.2 & \pm 8.1 & \pm 52.3 & \pm 9.6 & \pm 6.3 & \pm 61.3 & & \\
\hline \multirow[t]{2}{*}{ Antagonist: } & ТВ & 14.7 & 13.8 & 2.6 & 13.9 & 11.9 & -3.1 & 0.65 & 0.72 \\
\hline & & \pm 10.0 & \pm 9.0 & \pm 39.1 & \pm 6.7 & \pm 6.6 & \pm 49.9 & & \\
\hline
\end{tabular}


TABLE 4. Energy and macronutrient intake during the initial 3-wk RT (no nutritional intervention) and 12-wk RT (PLA or PRO supplementation) periods. During the 12-wk supplemented RT period, data include training and non-training days. Data are mean \pm SD and $P$-values are displayed for independent $t$-tests.

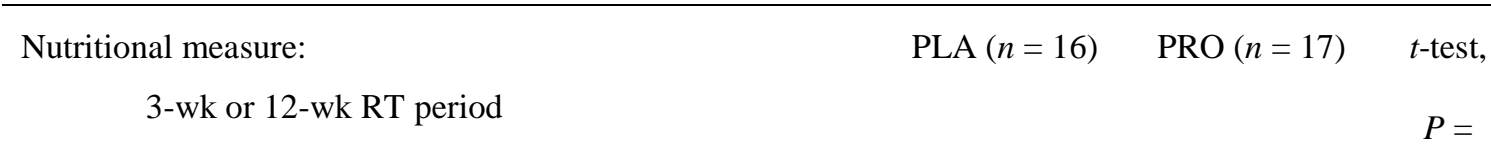

Energy intake:

3-wk RT $\left(\mathrm{kcal} \cdot \mathrm{d}^{-1}\right)$
12-wk RT - Normal diet $\left(\mathrm{kcal} \cdot \mathrm{d}^{-1}\right)$
12-wk RT - Total intake $\left(\mathrm{kcal} \cdot \mathrm{d}^{-1}\right)$

$\begin{array}{lll}2515 \pm 706 & 2482 \pm 581 & 0.89 \\ 2522 \pm 672 & 2480 \pm 608 & 0.85 \\ 2545 \pm 672 & 2572 \pm 608 & 0.91\end{array}$

Protein intake:

3-wk RT $\left(g \cdot \mathrm{d}^{-1}\right)$
3-wk RT $\left(\mathrm{g} \cdot \mathrm{kg}^{-1} \cdot \mathrm{d}^{-1}\right)$
12-wk RT - Normal diet $\left(\mathrm{g} \cdot \mathrm{d}^{-1}\right)$
12-wk RT - Normal diet $\left(\mathrm{g} \cdot \mathrm{kg}^{-1} \cdot \mathrm{d}^{-1}\right)$
12-wk RT - Total intake $\left(\mathrm{g} \cdot \mathrm{d}^{-1}\right)$
12-wk RT - Total intake $\left(\mathrm{g} \cdot \mathrm{kg}^{-1} \cdot \mathrm{d}^{-1}\right)$

$\begin{array}{ccc}101 \pm 21 & 95 \pm 26 & 0.39 \\ 1.36 \pm 0.35 & 1.28 \pm 0.37 & 0.41 \\ 101 \pm 28 & 100 \pm 23 & 0.85 \\ 1.35 \pm 0.47 & 1.33 \pm 0.32 & 0.88 \\ 101 \pm 28 & 117 \pm 23 & 0.09 \\ 1.35 \pm 0.47 & 1.56 \pm 0.33 & 0.12\end{array}$

CHO intake:

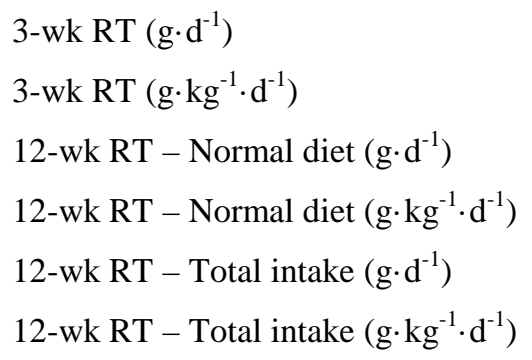

$\begin{array}{ccc}325 \pm 106 & 343 \pm 101 & 0.62 \\ 4.41 \pm 1.79 & 4.59 \pm 1.38 & 0.75 \\ 316.4 \pm 89 & 341 \pm 104 & 0.47 \\ 4.23 \pm 1.34 & 4.56 \pm 1.50 & 0.49 \\ 322 \pm 89 & 347 \pm 104 & 0.47 \\ 4.31 \pm 1.35 & 4.64 \pm 1.50 & 0.50\end{array}$

Fat intake:

$$
\begin{aligned}
& \text { 3-wk RT }\left(\mathrm{g} \cdot \mathrm{d}^{-1}\right) \\
& \text { 3-wk RT }\left(\mathrm{g} \cdot \mathrm{kg}^{-1} \cdot \mathrm{d}^{-1}\right) \\
& \text { 12-wk RT - Normal diet }\left(\mathrm{g} \cdot \mathrm{d}^{-1}\right) \\
& \text { 12-wk RT - Normal diet }\left(\mathrm{g} \cdot \mathrm{kg}^{-1} \cdot \mathrm{d}^{-1}\right)
\end{aligned}
$$

$\begin{array}{ccc}81 \pm 26 & 86 \pm 32 & 0.60 \\ 1.10 \pm 0.39 & 1.16 \pm 0.39 & 0.57 \\ 92 \pm 37 & 84 \pm 34 & 0.52 \\ 1.22 \pm 0.56 & 1.14 \pm 0.53 & 0.61\end{array}$




Resistance Training (RT) Measurements

Screening, PAL

Familiarization (1-RM, MVF)

1-RM, MVF

\begin{tabular}{|c|}
\hline $\begin{array}{c}\text { Initial RT } \\
\text { (3 weeks) }\end{array}$ \\
\hline No RT \\
(6 weeks) \\
\\
\\
Supplemented RT \\
(12 weeks) \\
PRO or PLA \\
before and after \\
each RT session \\
\end{tabular}

Nutrient intake

1-RM, MVF, MRI, US, anthropometry

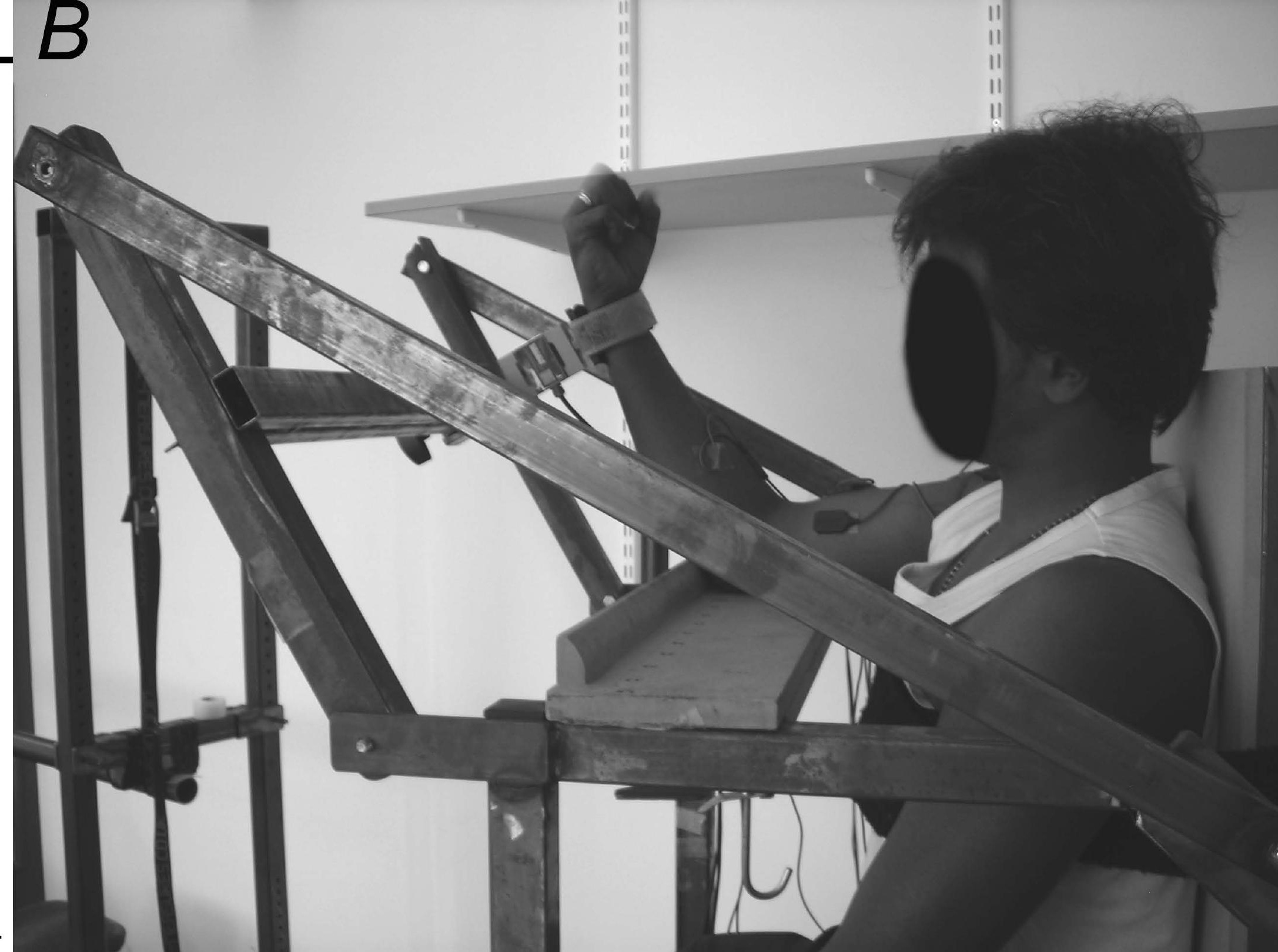

Nutrient intake

\section{1-RM, MVF}

Nutientintake
1-RM, MVF, MRI, US, anthropometry, PAL

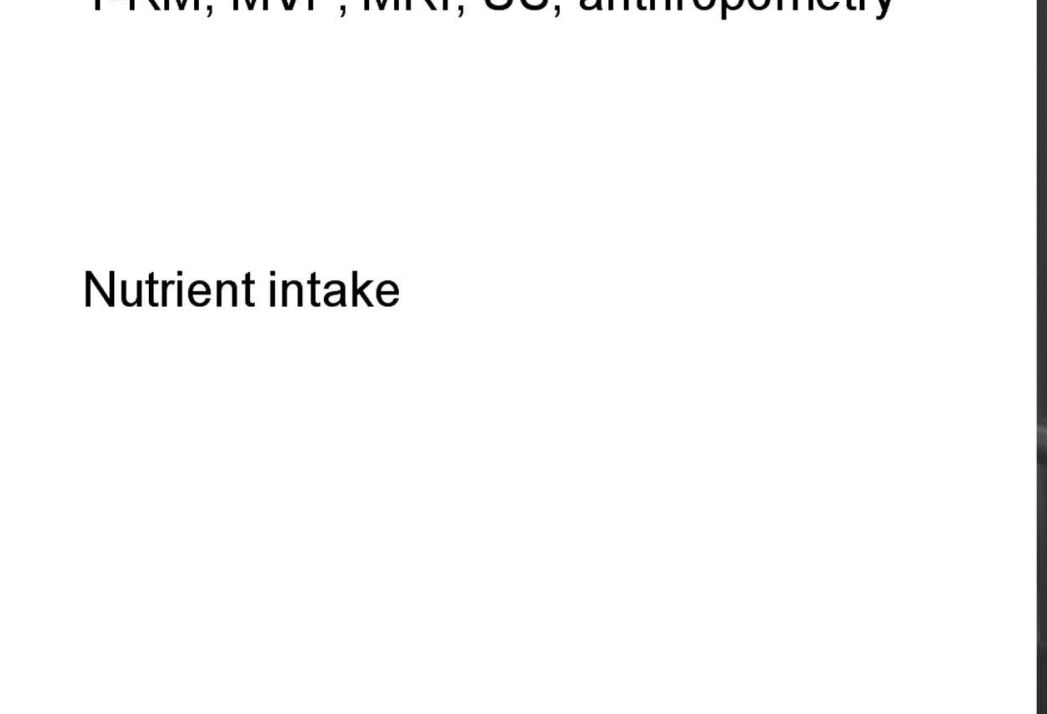



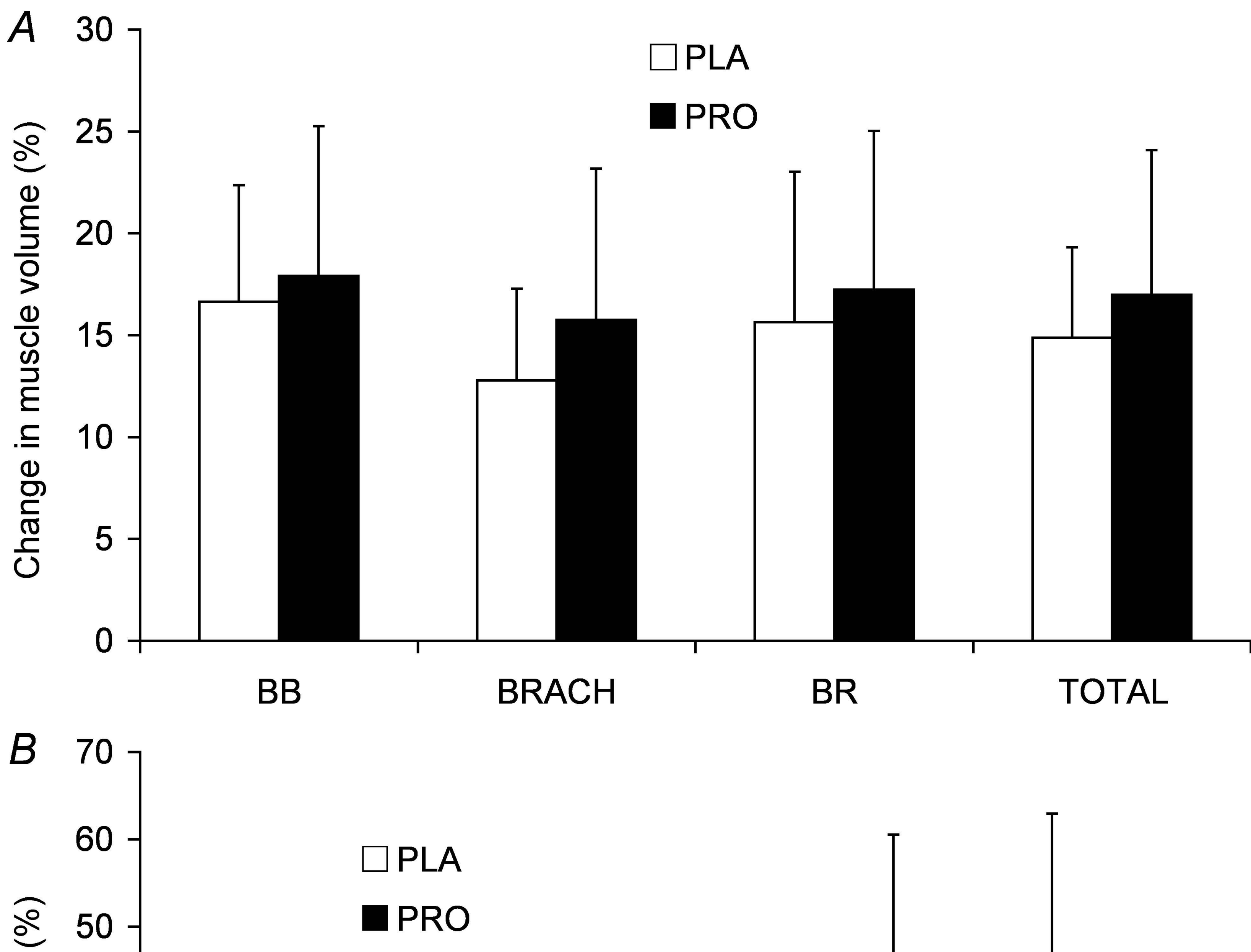

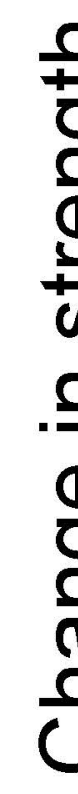

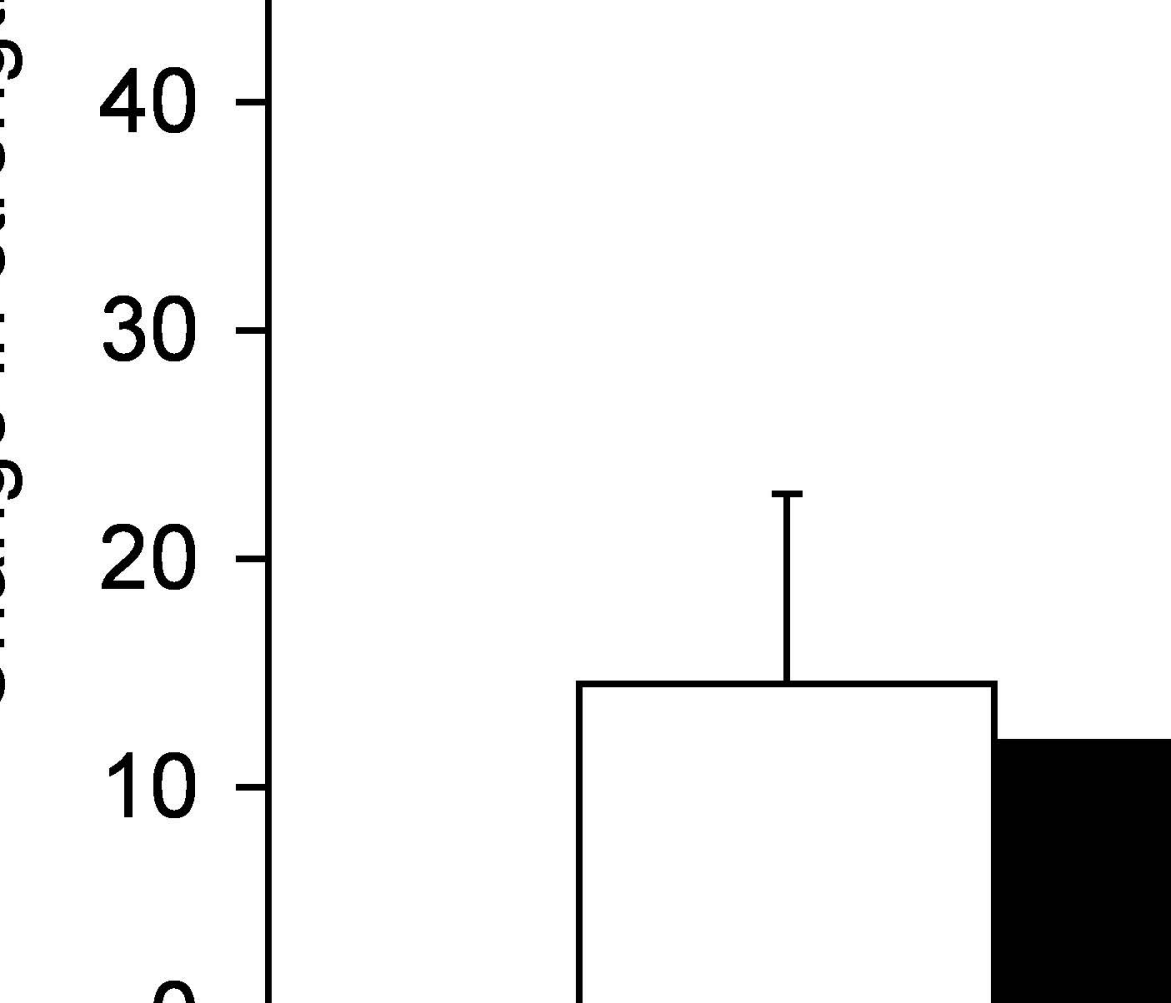

MVF 